\title{
Gloomy pharma forecast in Japan downgraded after quake
}

Japan is the world's second largest pharmaceutical market after the US on the basis of total revenue. But according to Business Monitor International (BMI), a London-based analyst firm, Japan's overall pharmaceutical market is stagnating, and the devastating 9.0-magnitude earthquake that struck in March has introduced new uncertainties. In its initial review, published in early March, BMI stated that factors such as the government's cuts to subsidies for prescription medicines and its pro-generics stance will conspire to lower annual growth rates going forward. Presently, pharmaceutical expenditure is $1.8 \%$ of the country's gross domestic product and BMI predicted that through to 2015 the five-year compound annual growth rate will be $0.7 \%$. However, soon after BMI published these gloomy estimates, they revised them down further. The 11 March earthquake and tsunami that devastated a large part of northeastern Japan led the firm to downgrade its pharmaceutical market forecast to take into account the impending economic slowdown.
"The majority of the report's content is still applicable, but we have lowered our 2020 sales predictions by $1.5 \%$ (from $\$ 91.7$ billion to $\$ 90.3$ billion), which reflects a change in the country's overall macroeconomics now that the full extent of the recent disaster is known," says Jamie Davies, BMI analyst and report author. "To improve their overall outlook for growth, the country's pharmaceutical companies need to look more to emerging markets, such as China."

Mihoko Shinomiya, a spokesperson for Takeda Pharmaceutical Co., says that so far Takeda products have been unaffected by the recent quake and tsunami. "Our production facilities are far from the affected region," she said. Astellas Pharma, Japan's second largest drug company, are not so fortunate. They have two manufacturing facilities in the devastated regions both of which were damaged. "Our Nishine formulating and packaging plant has now resumed normal operations, but our biggest challenge is to repair and reopen the Takahagi plant," says Daisuke Okajima, a spokesperson for
Astellas. The economic impact of the recent events on Astellas's business is still being assessed, but the company reports having a three-month supply of their mainstay products stockpiled. The cost of repair and reconstruction efforts in Japan is likely to make the March earthquake and tsunami one of the costliest natural disasters in history. Shin-Ichi Nishikawa, deputy director of the Riken Center for Developmental Biology in Kobe, says it's hard to tell what impact this will have on future budgets for scientific research, but, at a meeting with the Ministry of Education in mid-April, the plan was to continue to fund all new projects.Riken's current focus is on helping colleagues replace damaged scientific equipment and replenish resources. Many resources were lost in the power cuts, Nishikawa notes. "We, and many other scientists around Japan, are organizing a collection of goods"-such as equipment that is not currently being used-"for our colleagues in the devastated regions," he says.

Branwen Morgan

\section{Experts emphasize need for speed in launch of Australian trials}

SYDNEY - This past December, Oprah Winfrey took 300 of her audience members on a much-publicized trip to Australia to celebrate the twenty-fifth anniversary of her US talk show. But it's going to take more than an Oprah endorsement or a catchy advertising campaign for the land Down Under to remain a preferred destination for the conduct of clinical trials.

As recently as 2005, the Economist Intelligence Unit conducted a benchmarking study that ranked Australia as the number one location for conducting clinical trials. It was placed ahead of countries such as the US, Japan and India on the basis of its high number of trial sites per capita, high percentage of on-time trial completions and low average trial costs.

But times have changed. Data from Australia's main drug regulatory agency, the Therapeutic Goods Administration, shows that the number of new trials recorded there has dropped to 574, a level last seen in 2001.

Vlado Perkovic, executive director of the clinical trials arm of the George Institute for Global Health in Sydney, cites competition from emerging countries and higher operating costs as contributing factors to Australia losing its attractiveness as a prime clinical trial location. Additionally, he says the regulatory process is not yet streamlined. "You may now have up to fifty sites participating in a trial, each of which has to go through the separate ethics and research governance processes-this can drag on for months, if not years," he says.

The government-initiated panel known as the Clinical Trials Action Group (CTAG) has addressed many of these issues in a report released in March. As a solution to slow start-up times, the report urges that Australia's National Health and Medical Research Council (NHMRC) implement the harmonization of multicenter ethical review (HoMER) system by July 2011.

The HoMER scheme, which will enable institutions collaborating in a multicenter clinical trial to recognize and accept the review of a single ethics committee, has experienced a number of delays since its launch in 2006.

The new report proposes incentives to reach one-month timelines for processes such as ethics reviews, a measure its authors say will enhance efficiency and aid promotion of Australia's global competitiveness. Notably, this would give Australia an edge over the EU, where countries are required to complete both ethics and governance reviews within 60 calendar days.

The CTAG sees the HoMER scheme as being central to reducing some current regulatory complexities. Its report adds that the research governance process has suffered because of ambiguities in the roles and responsibilities of different parties and recommends that a bestpractice guide be adopted by July.

Warwick Anderson, NHMRC chief executive, says the agency is on time to deliver on the proposals that relate to the NHMRC, but that most of the recommendations are directed at the Australian Health Ministers' Advisory Council.

"The NHMRC will publish a research governance best-practice handbook by July, but we can only set the framework," he says. "The state and territory health departments are responsible for the hospitals and will need to work with them to implement new processes and procedures."

Branwen Morgan 